\title{
Efficacy of Curcumin as an Adjunct to Scaling and Root Planing in Chronic Periodontitis Patients: A Randomized Controlled Clinical Trial
}

\author{
Kepu V Raghava ${ }^{1}$, Kalyani P Sistla², Sarita J Narayan ${ }^{3}$, Umesh Yadalam ${ }^{4}$, Aditi Bose ${ }^{5}$, Kiran Mitra ${ }^{6}$
}

\begin{abstract}
Aim: The aim of the present study is to evaluate the efficacy of curcumin gel as local drug delivery post-scaling and root planing and its effect on clinical parameters like plaque, gingival scores, pocket depth, and clinical attachment level (CAL).

Materials and methods: Ten patients with two sites in the contralateral quadrants having probing pocket depths (PPDs) of $\geq 5 \mathrm{~mm}$ were selected. Full-mouth scaling and root planing (SRP) was performed followed by the application of curcumin gel on a single side. Assessment of plaque index (PI), gingival index (GI), PPD, and CALs were done at the baseline and at the 4th week.

Results: The results revealed that there was a statistically significant reduction in PI and probing depth in the test group when compared with the control group. CAL was improved but the results were not statically significant.

Conclusion: The local application of curcumin gel when used in conjunction with SRP showed a significant improvement in periodontal parameters and has a beneficial effect in patients with chronic periodontitis.

Clinical significance: Curcumin gel as an adjunct to SRP showed a marked improvement in restoring gingival health by an improvement in clinical parameters. It has proven properties like anti-inflammatory, antioxidant, antimicrobial, hepatoprotective, immunostimulant, antiseptic, antimutagenic, and it also accelerates wound healing. It may be a more acceptable and viable option for the common man. Curcumin can be used as an effective alternative local drug delivery agent.

Keywords: Curcumin, Local drug delivery, Periodontitis, Scaling and root planing.

The Journal of Contemporary Dental Practice (2019): 10.5005/jp-journals-10024-2608
\end{abstract}

\section{INTRODUCTION}

Periodontitis and dental caries are among the two most prevalent diseases of the oral cavity. Dental plaque and calculus are the prerequisite for any of periodontal diseases and complete elimination of plaque and calculus is the basic goal of any periodontal treatment. Chemotherapeutic agents in adjunct to mechanical debridement were used to enhance the efficiency of the conventional therapy. Due to limitations of the usage of systemic antibiotics for periodontal procedures, local drug delivery system has gained popularity over a period of time.

Turmeric (Curcuma longa) is an Indian spice derived from the rhizomes belonging to Zingiberaceae family. The name curcumin longa is derived from the Persian word, "kirkum," which means saffron. The primary active constituent of turmeric and the one responsible for its vibrant yellow color is "curcumin" which was first identified in 1910 by Lampe and Milobedzka.

The active constituents of turmeric include the three curcuminoids: curcumin (diferuloylmethane), demethoxycurcumin, and bisdemethoxycurcumin, as well as volatile oils (turmerone, atlantone, and zingiberone), sugars, proteins, and resins. Curcumin exhibits anti-inflammatory, antioxidant, anticarcinogenic, antiviral, and antimicrobial activities. Curcumin modulates the inflammatory response by down-regulating the activity of cyclooxygenase-2, lipoxygenase, and inducible nitric oxide synthase enzymes and inhibits the production of the inflammatory cytokine.

The present study was designed to evaluate the efficacy of curcumin gel as a local drug delivery agent following SRP and its effect on clinical parameters like plaque, gingival scores, pocket depth, and CAL. $\overline{{ }^{1-6} \text { Department of Periodontology, Sri Rajiv Gandhi College of Dental }}$ Sciences and Hospital, Bengaluru, Karnataka, India

Corresponding Author: Kepu V Raghava, Department of Periodontology, Sri Rajiv Gandhi College of Dental Sciences and Hospital, Bengaluru, Karnataka, India, Phone: +91 9844330760, e-mail: vijaykepu@yahoo.com

How to cite this article: Raghava KV, Sistla KP, et al. Efficacy of Curcumin as an Adjunct to Scaling and Root Planing in Chronic Periodontitis Patients: A Randomized Controlled Clinical Trial. J Contemp Dent Pract 2019;20(7):842-846.

Source of support: Nil

Conflict of interest: None

The objective of the present study is to compare curcumin with SRP as compared with SRP alone in the treatment of the chronic periodontitis.

\section{Materials and Methods}

The present study was a randomized split-mouth study. The study population included 10 subjects aged $25-40$ years reported at the Department of Periodontology and Implantology, Sri Rajiv Gandhi College of Dental Sciences and were subsequently diagnosed as chronic periodontitis patients. Approval of the study was obtained from the Ethical Committee and Institutional Review Board of Sri Rajiv Gandhi College of Dental Sciences and an informed consent was taken from all participants before commencing of the study.

(c) The Author(s). 2019 Open Access This article is distributed under the terms of the Creative Commons Attribution 4.0 International License (https://creativecommons. org/licenses/by-nc/4.0/), which permits unrestricted use, distribution, and non-commercial reproduction in any medium, provided you give appropriate credit to the original author(s) and the source, provide a link to the Creative Commons license, and indicate if changes were made. The Creative Commons Public Domain Dedication waiver (http://creativecommons.org/publicdomain/zero/1.0/) applies to the data made available in this article, unless otherwise stated. 


\section{Inclusion Criteria}

- Patients willing to take part in the study.

- Subjects of the age group between 25 and 40 years without any systemic disease.

- Patient with more than 20 natural teeth.

- Patient with chronic periodontitis having a PPD of $\geq 5 \mathrm{~mm}$.

- Patients with no history of allergies.

\section{Exclusion Criteria}

- Pregnant woman and lactating mothers.

- Teeth with both endo-perio lesions.

- Patient with use of tobacco or tobacco related products.

- Patient on antibiotics within 3 months prior to the study.

- Patients having systemic diseases like diabetes mellitus, hypertension, bleeding disorders, hyperparathyroidism, and compromised medical conditions.

- Patients who have had periodontal treatment in the last 6 months.

\section{Study Design}

Two sites were identified in 10 patients diagnosed severe chronic periodontitis (AAP 1999 classification) and were randomly allocated to a test site and a control site by coin toss:

- Group I (control) - only SRP was done at the baseline visit.

- Group II (test) - SRP was followed by local application of curcumin at the baseline visit.

Full-mouth SRP was performed followed by the application of curcumin gel on the test site and only SRP on the control site.

Clinical parameters were measured on the baseline and after the 4-week follow-up in either site.

\section{Clinical Parameters Evaluated}

The parameters recorded were PI (Silness and Loe, 1964), GI (Loe and Silness, 1963), periodontal pocket depth (measured from the crest of gingival margin to base of the sulcus), and clinical attached level (cementoenamel junction to the base of the pocket).

\section{Procedure}

The test and control sites were selected on a random basis and, after full-mouth SRP, saline irrigation was done in both test and control sites and placement of medication was done only after complete bleeding was halted. The test site was completely isolated with cotton rolls (not to contaminate the medication with saliva) $2 \mathrm{mg}$ of undiluted curcumin gel through a $2 \mathrm{~mL}$ disposable syringe was placed in the test site and later the area was covered by Coe pack (for retaining the medicine in the pocket). Subjects were instructed not to touch the area till the removal of the pack. Patients were recalled after a week for Coe pack removal and refrained from using any other oral hygiene measures in the observation period, recalled after a month for follow-up.

\section{Results}

An interventional split-mouth study in 10 patients ( 5 females and 5 males) was conducted over a period of 4 weeks. There was a significant reduction in $\mathrm{PI}$ values from the baseline to the follow-up visit (Table 1 and Fig. 1). There was a reduction in GI scores in this study which was not significant when compared between the test and the control site $(p=1>0.05)$. This may be due to the elimination of local etiologic factors (plaque and calculus) which harbor numerous pathogenic bacterial strains.
Table 1: Mean values of gingival and and probing depth and clinical attachment loss of case and control at the baseline and after 4 weeks

\begin{tabular}{lllll}
\hline $\begin{array}{l}\text { Case } \\
\text { baseline }\end{array}$ & $\begin{array}{l}\text { Case } 4 \\
\text { weeks }\end{array}$ & $\begin{array}{l}\text { Control } \\
\text { baseline }\end{array}$ & $\begin{array}{l}\text { Control } \\
4 \text { weeks }\end{array}$ & Gl \\
\hline 1.76 & 0.42 & 1.71 & 0.43 & Mean \\
0.13515 & 0.10088 & 0.15667 & 0.10225 & SD \\
\hline $\begin{array}{l}\text { Case } \\
\text { baseline }\end{array}$ & $\begin{array}{l}\text { Case } 4 \\
\text { weeks }\end{array}$ & $\begin{array}{l}\text { Control } \\
\text { baseline }\end{array}$ & $\begin{array}{l}\text { Control } 4 \\
\text { weeks }\end{array}$ & $\begin{array}{l}\text { Plaque } \\
\text { index }\end{array}$ \\
\hline 1.71 & 0.43 & 1.85 & 0.41 & Mean \\
0.15667 & 0.10225 & 0.12225 & 0.10483 & SD \\
\hline $\begin{array}{l}\text { Case } \\
\text { baseline }\end{array}$ & $\begin{array}{l}\text { Case } 4 \\
\text { weeks }\end{array}$ & $\begin{array}{l}\text { Control } \\
\text { baseline }\end{array}$ & $\begin{array}{l}\text { Control } 4 \\
\text { weeks }\end{array}$ & PPD \\
\hline 4.645 & 2.634 & 4.4 & 2.634 & Mean \\
0.20021 & 0.1526 & 0.2812 & 0.1526 & SE \\
\hline $\begin{array}{l}\text { Case } \\
\text { baseline }\end{array}$ & $\begin{array}{l}\text { Case } 4 \\
\text { weeks }\end{array}$ & $\begin{array}{l}\text { Control } \\
\text { baseline }\end{array}$ & $\begin{array}{l}\text { Control } 4 \\
\text { weeks }\end{array}$ & CAL \\
\hline 4.73 & 2.548 & 4.413 & 2.913 & Mean \\
0.2368 & 0.50177 & 0.8092 & 0.82173 & Variance \\
\hline
\end{tabular}

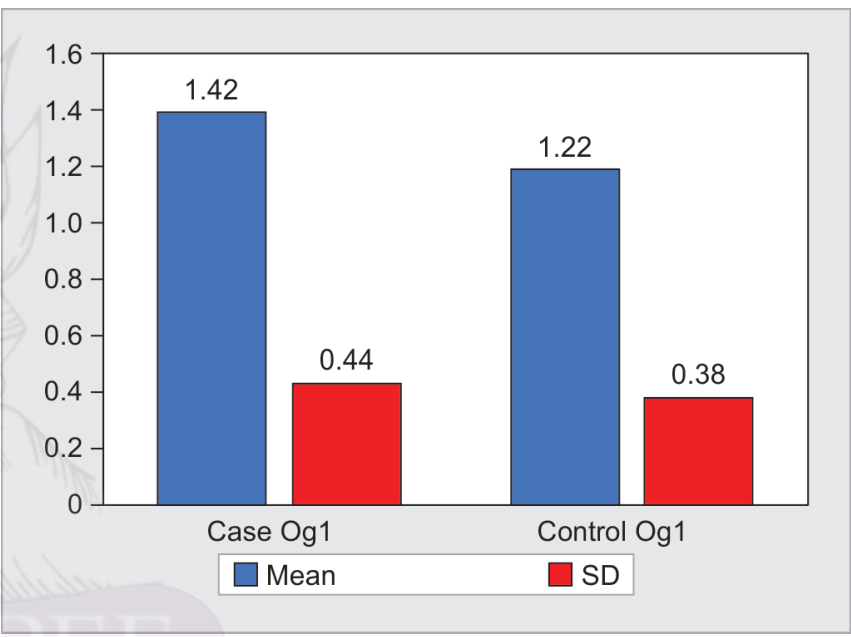

Fig. 1: PI change from baseline to the 4 th week

The difference in mean PPD reductions was significant $(p=0.01)$ at the test site when compared with the control site after 4 week evaluation (Table 2 and Fig. 2) but the change in pocket reduction had no statically significance in case and control. There was a good amount of improvement in CAL before and after and almost neared the significance value statically ( $p=0.06$ ) (Table 3 and Fig. 3 ).

\section{Discussion}

An interventional split-mouth study in 10 patients ( 5 females and 5 males) was conducted over a period of 4 weeks and, on evaluation of $\mathrm{Gl}$ and $\mathrm{PI}$ on the baseline and after a 4-week follow-up, there was a decrease in both the indices in both the groups but the decrease

Table 2: Change of PI from baseline to the 4th week

\begin{tabular}{lll}
\hline $\begin{array}{l}\text { Change from baseline } \\
\text { to the 4th week (PI) }\end{array}$ & SD & Mean \\
\hline Case & 0.44 & 1.42 \\
Control & 0.38 & 1.22 \\
\hline
\end{tabular}




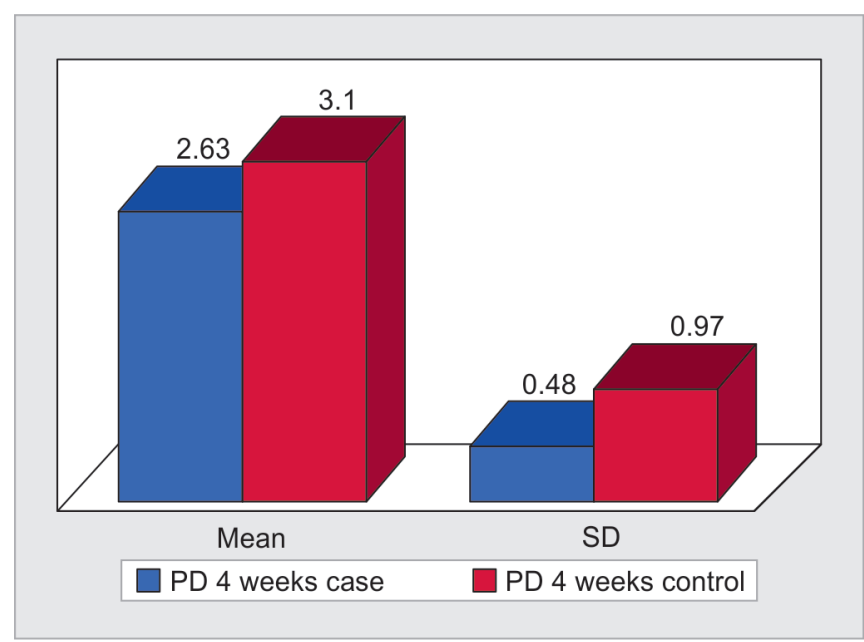

Fig. 2: Pocket depth assessment at the follow-up

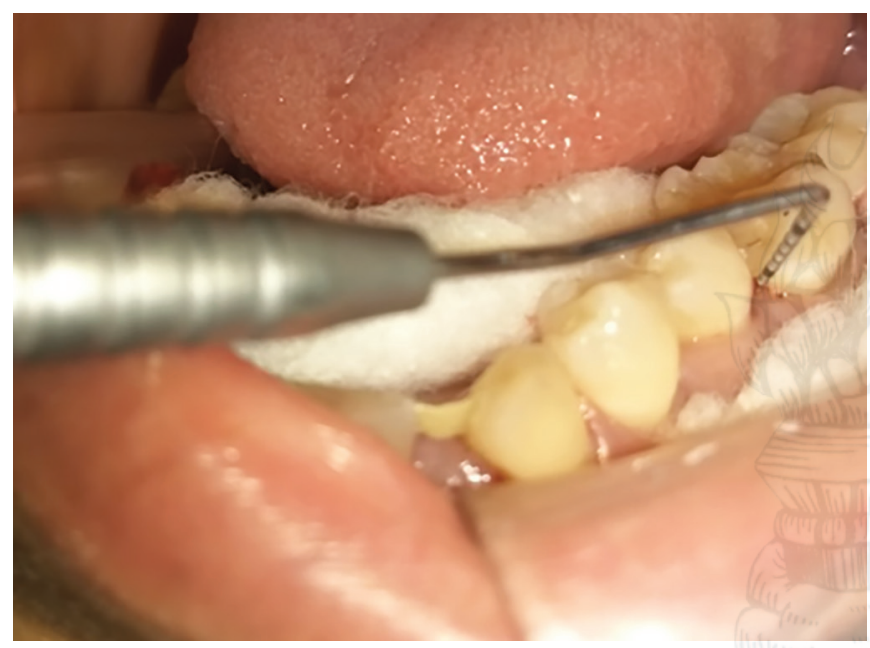

Fig. 4: Probing depth measured with UNC 15 probe

Table 3: Change of probing depth from baseline to the 4th week

\begin{tabular}{lll}
\hline PD at follow-up (4 weeks later) & $S D$ & Mean \\
\hline Case & 0.48 & 2.63 \\
Control & 0.97 & 3.10 \\
\hline
\end{tabular}

$p$ value $=0.04 ;<0.05$ (statically significant)

was significant in Pl after 4 week evaluation (Table 4). The test group has shown better improvement in PI when compared to the control group. The results of the present study were similar to the studies done by Nagasri et al. (Fig. 4).

The improvement in the plaque and gingival status might be attributed to the fact that there was a reduction in supragingival plaque after SRP and oral hygiene instructions received during the preliminary visit. ${ }^{1}$

However, studies done by Anuradha et al. showed contrasting results where there was no significance in both $\mathrm{Gl}$ and $\mathrm{PI}^{2}$

Table 4: Change of CAL from baseline to the 4th week

\begin{tabular}{lll}
\hline CAL at follow-up (4 weeks later) & SD & Mean \\
\hline Case & 0.71 & 4.41 \\
Control & 0.91 & 2.54 \\
\hline
\end{tabular}

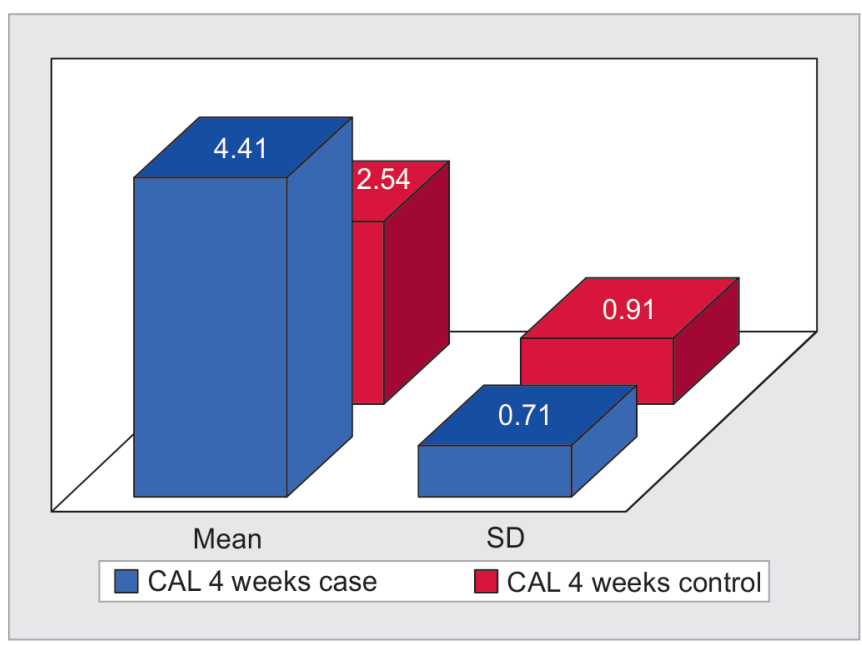

Fig. 3: Pocket depth assessment at the follow-up

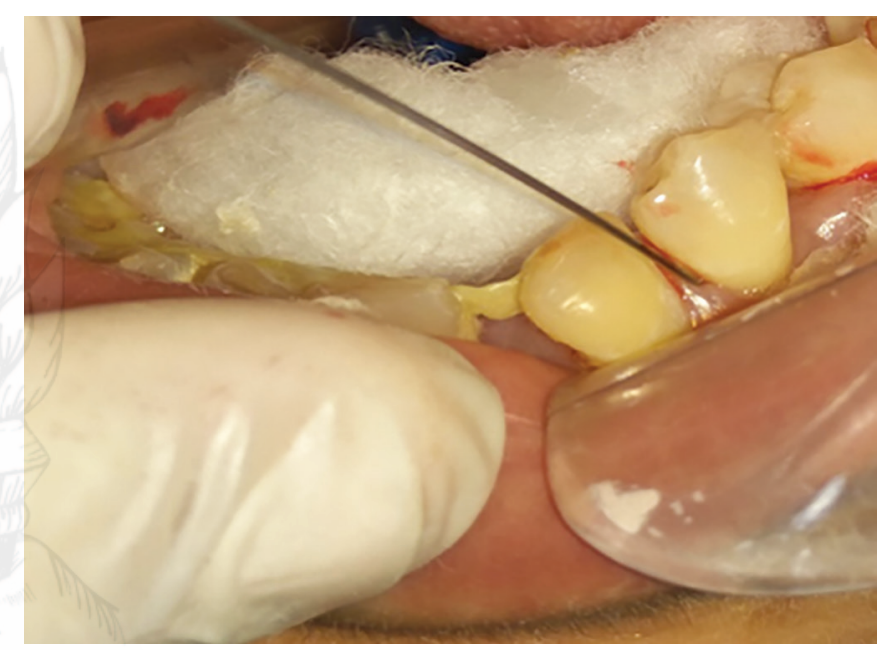

Fig. 5: Curcumin local drug delivered through a $2 \mathrm{~mL}$ syringe needle

The difference in mean PPD reductions was significant at the test site when compared to the control site when evaluated 4 weeks after the procedure. The results were in accordance with Colombo et al. ${ }^{3}$ and Behal et al. ${ }^{4}$

This can be attributed to an anti-inflammatory mechanism of curcumin which modulates the inflammatory response, inhibits the production of pro-inflammatory cytokines, represses the activation of AP-1 and NF-k $\beta$, inhibits the biosynthesis of inflammatory prostaglandins, and enhances neutrophil function during the inflammatory response. It may also be due to the effectiveness of SRP in the overall gain of periodontal attachment as well as a decrease in the percent of sites with supragingival biofilm accumulation and gingival inflammation (Fig. 5). ${ }^{3}$

Contrasting results were seen in studies done by Anuradha et al. $^{2}$ and Nandini et al. ${ }^{5}$

There was a good amount of improvement in CAL before and after and almost neared the significance value statically $(p=0.06)$. The results of the present study were in agreement with Nagasri et al., Behal et al., and Hugar et al. ${ }^{6}$

Studies also showed contrasting results. Anuradha et al. and Nandini et al. have showed that there was an improvement in the clinical attachment level but the improvement was not statically significant (Fig. 6). 


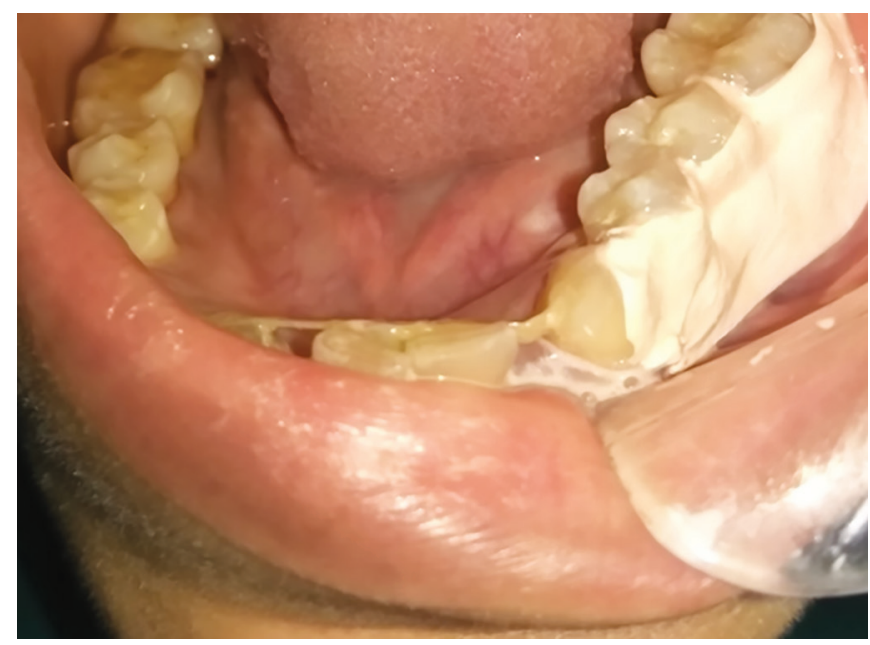

Fig. 6: Periodontal Coe pack placed on the test site

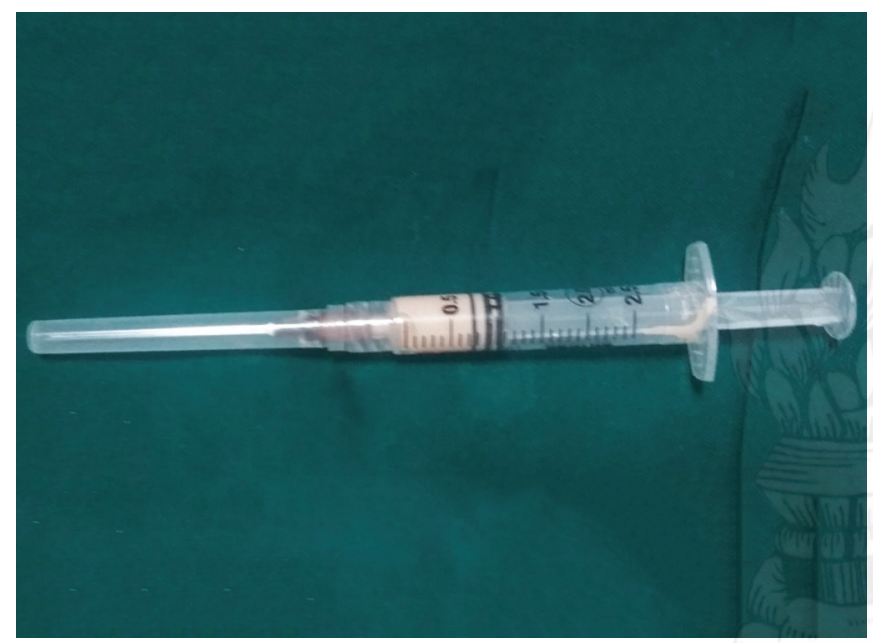

Fig. 8: Curcumin gel loaded in a disposable syringe

Curcumin has been a subject of interest for research in recent times. Many studies were being done to confirm the efficacy of curcumin as an adjunct to local drug delivery. Studies done by Sruthima et al. ${ }^{7}$ and Anitha et al. ${ }^{8}$ have compared curcumin with chlorhexidine (gold standard) and results have shown that curcumin was equally effective (Fig. 7).

A review by Chainani-Wu ${ }^{9}$ and Akram et al. ${ }^{10}$ has concluded that curcumin has been demonstrated to be safe in six human trials and has demonstrated anti-inflammatory activity. It may exert its anti-inflammatory activity by inhibition of a number of different molecules that play a role in inflammation which is also seen in the present study as the levels of inflammation in gingiva has come down from the baseline visit of the patient which was well appreciated in the clinical features of gingiva like color, consistency, and shape and was supported by improved clinical parameters like gingival and PI (Fig. 8).

\section{Conclusion}

The local application of curcumin in conjunction with SRP showed an improvement in periodontal parameters and has a beneficial effect in patients with chronic periodontitis. This study also concludes that thorough SRP with an efficient adjunct reduces the necessity of open flap debridement to an extent.

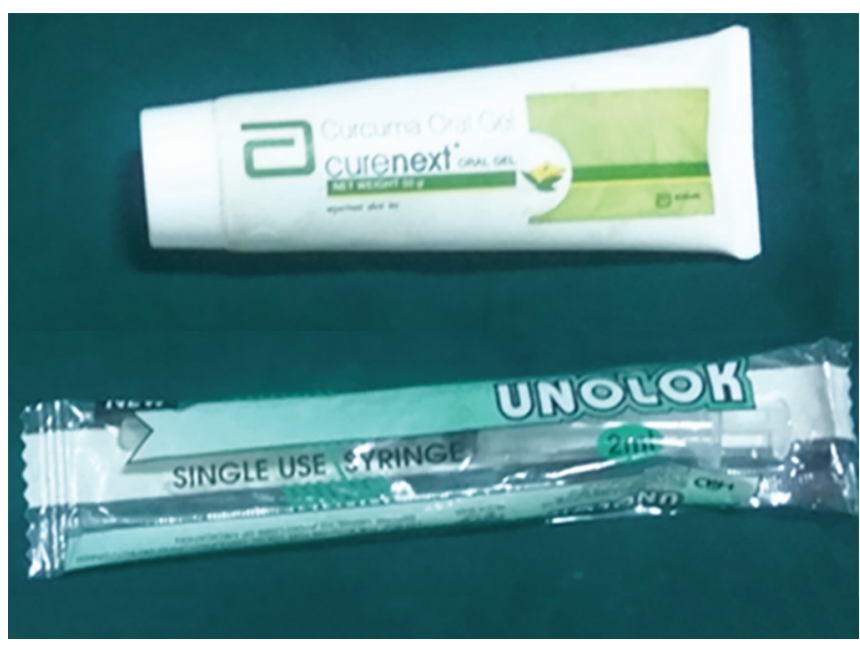

Fig. 7: Curenext curcumin gel and a $2 \mathrm{~mL}$ disposable syringe

\section{Clinical Significance}

Dental plaque and calculus are the prerequisite for any of periodontal diseases and complete elimination of plaque and calculus is the basic goal of any periodontal treatment.

Curcumin gel as an adjunct to SRP shows marked improvement in restoring gingival health by improvement in clinical parameters. It has a wide biological spectrum of activity like anti-inflammatory, antioxidant, antimicrobial, hepatoprotective, immunostimulant, antiseptic, antimutagenic, and it also accelerates wound healing that could provide clinicians with an alternative anti-inflammatory and antimicrobial agent for managing a variety of chronic diseases, including periodontal diseases. ${ }^{11-15}$ It may be a more acceptable and viable option for the common man. Curcumin can be used as an effective alternative local drug delivery agent.

\section{Limitations of the Study}

There is a scarcity of information and research in this field. Therefore, further research is required to determine the optimal dosage and bio-efficacy of curcumin-based drugs.

One of the major problems with developing curcumin for clinical efficacy is its low oral bioavailability that can be due to its poor absorption, high rate of metabolism in the intestines, and rapid elimination from the body.

The results obtained in our present study showed that the local application of curcumin in conjunction with SRP has shown improvement in periodontal parameters and have a beneficial effect in patients with chronic periodontitis. The study was conducted on a modest sample of 10 subjects, and studies with larger sample sizes need to be carried out in future to endorse the results observed in our study.

\section{References}

1. Nagasri $M$, Madhulatha $M$, et al. Efficacy of curcumin as an adjunct to scaling and root planning in chronic periodontitis patients: a clinical and microbiological study. J Pharm Bioallied Sci 2015;7:S554-S558. DOI: 10.4103/0975-7406.163537.

2. Anuradha BR, Bai YD, et al. Evaluation of anti-inflammatory effects of curcumin gel as an adjunct to scaling and root planing: a clinical study. J Int Oral Health 2015;7(7):90-93.

3. Colombo AP, Teles RP, et al. Effects of non surgical mechanical therapy on the subgingivalmicrobiota of Brazilians with untreated chronic periodontitis: 9-month results. J Periodontol 2005;76:778-784. DOI: 10.1902/jop.2005.76.5.778. 
4. Behal R, Mali AM, et al. Evaluation of local drug-delivery system containing $2 \%$ whole turmeric gel used as an adjunct to scaling and root planing in chronic periodontitis: a clinical and microbiological study. J Indian Soc Periodontol 2011;15(1):35-38. DOI: 10.4103/0972124X.82264.

5. Nayyar N, Vidya D, et al. Comparative evaluation of $1 \%$ curcumin solution and $0.2 \%$ chlorhexidine irrigation as an adjunct to scaling and root planing in management of chronic periodontitis: a clinicomicrobiological study. J Pharm Biomed Sci 2012;14(03):1-7.

6. Hugar SS, Patil S, et al. Influence of application of chlorhexidine gel and curcumin gel as an adjunct to scaling and root planing: a interventional study. J Nat Sci Biol Med 2016;7(2):149-154. DOI: 10.4103/0976-9668.184701.

7. Gottumukkala SN, Sudarshan S, et al. Comparative evaluation of the efficacy of two controlled release devices: chlorhexidine chips and indigenous curcumin based collagen as local drug delivery systems. Contemp Clin Dent 2014 Apr;5(2):175-181. DOI: 10.4103/0976237X.132310.

8. Anitha V, Rajesh P, et al. Comparative evaluation of natural curcumin and synthetic chlorhexidine in the management of chronic periodontitis as a local drug delivery: a clinical and microbiological study. Indian J Dent Res 2015 Jan-Feb;26(1):53-60. DOI: 10.4103/0970-9290.15680.
9. Chainani-Wu N. Safety and anti-inflammatory activity of curcumin: a component of tumeric (Curcuma longa). J Altern Complement Med 2003;9(1):161-168. DOI: 10.1089/107555303321223035.

10. Akram M, Shahabuddin A, et al. Curcuma longa and curcumin: a review article. Rom J Biol Plant Biol 2011;55(2):65-70.

11. Angiolella $L$, Sacchetti $G$, et al. Antimicrobial and antioxidant activities of natural compounds. Evid Based Complement Alternat Med 2018;2018:1945179. DOI: 10.1155/2018/1945179.

12. Fakruddin M, Mannan KS, et al. Antibacterial, antifungal and antioxidant activities of the ethanol extract of the stem bark of Clausena heptaphylla. BMC Complement Altern Med 2012;12:232. DOI: 10.1186/1472-6882-12-232.

13. Sant $A$, Dhave $D$, et al. Comparative evaluation of anti-microbial efficacy of curcuma oral gel and chlorhexidine gel on the periodontal pathogens: an in vitro study. IEJDTR 2017;6(1):386-389.

14. Choudhary M, Kumar V, et al. Medicinal plants with potential antiarthritic activity. J Intercult Ethnopharmacol 2015;4(2):147-179. DOI: $10.5455 /$ jice.20150313021918.

15. Jaswal R, Dhawan S, et al. Comparative evaluation of single application of $2 \%$ whole turmeric gel vs $1 \%$ chlorhexidine gel in chronic periodontitis patients: a pilot study. J Indian Soc Periodontol 2014;18(5):575-580. DOI: 10.4103/0972-124X.142445. 